\title{
El acuerdo para el fortalecimiento de la asociación económica entre México y Japón. Los esquemas de cooperación como incentivo para impulsar sectores estratégicos en México
}

DOI: $10.32870 /$ mycp.v14i41.367

María Elena Romero Ortiz Martha Loaiza Becerra Emma Mendoza Martínez ${ }^{1}$

\section{Resumen}

$\mathrm{E}$ 1 Acuerdo de Asociación Económica entre México y Japón firmado en el año 2005 abrió una nueva era en las relaciones entre ambos países, este acuerdo significa la posibilidad de mantener y aprovechar prósperas relaciones comerciales y especialmente continuar con los programas de cooperación bilateral contenidos en el capítulo 14 del acuerdo. La cooperación entre ambas naciones puede ser una herramienta eficiente para impulsar el desarrollo de tecnología, apoyar a las pequeñas y medianas empresas, propiciar la educación y capacitación técnica, así como para cuidar la conservación del medio ambiente. Si bien es importante destacar que el acuerdo tiene como finalidad el beneficio para ambas naciones participantes, México - con el conocimiento y estrategias adecuadas - será quien mejor y mayor beneficio pueda obtener a partir de dos considerandos: primero, México, por su desarrollo macroeconómico ya no es sujeto de asistencia

1. Universidad de Colima. 
externa, y este acuerdo brinda la opción de continuar obteniendo apoyos de Japón y, segundo, por medio de este instrumento México puede encontrar los recursos para subsanar problemas de desarrollo a través del apoyo japonés en los sectores mencionados.

Palabras clave: cooperación México-Japón, ciencia y tecnología, educación, medio ambiente, pequeñas y medianas empresas, asociación económica

\section{Abstract}

The Economic Association Agreement signed in 2005 between Mexico and Japan opened a new era in the relationships among these countries, this Agreement representing the possibility of keeping and benefiting the prosperous commercial relationships and specially coping with the bilateral cooperation programs within Chapter 14 of the Agreement. The cooperation among these countries can be an efficient tool to boost the technological development, support small and medium enterprises (SMEs), educational and technical qualifications, and environmental conservation. Although it is important to highlight that the Agreement aims to benefit both participant nations, Mexico, with the knowledge and suitable strategies will be the one who obtains better and major benefits considering two facts: firstly, Mexico, by its macroeconomic development is no longer object of external assistance, and this Agreement provides the option of getting constant support from Japan and, secondly, through this tool Mexico can find resources to retrieve development problems through the Japanese support in the mentioned sectors.

Keywords: Mexico-Japan cooperation, Science and Technology, Education, Environment, Renewable Energies, Small and Medium Enterprises, Economic Association.

\section{Introducción}

Las relaciones entre México y Japón están permeadas por una importante distancia geográfica y cultural. ¿Por qué Japón invertiría tiempo y esfuerzo para concretar un acuerdo con México, cuando en términos comerciales la relevancia de nuestro país es mínima en comparación con otras naciones, particularmente del sureste asiático? Basta tan sólo con mencionar el déficit de 3 mil 892 millones 705 mil dólares que Japón tuvo con Malasia en el año 2009 o los 12 mil 490 millones 982 mil dólares que tuvo con Indonesia en 
el mismo año, mientras que con México alcanzó un superávit de 4 mil 036 millones 857 mil dólares el año pasado (METI, 2010).

La firma del Acuerdo para el Fortalecimiento de la Asociación Económica entre México y Japón (de aquí en adelante: AFAEMJ) parece estar sostenida en la iniciativa japonesa de no perder su competitividad en la región y gozar del mismo trato preferencial que Estados Unidos y Canadá ya tenían a través del Tratado de Libre Comercio de América del Norte (TLCAN) y del Acuerdo de Libre Comercio con la Unión Europea. Japón está interesado específicamente en la competitividad de sectores como el automotriz y el electrónico. ${ }^{2}$ Este objetivo ha sido tan importante que el sector empresarial impulsó la firma del acuerdo, provocando que el Ministerio de Economía, Comercio e Industria funcionara como un esquema para impulsar la diversificación comercial y sentar los precedentes para establecer nuevas modalidades de negociación basadas en la liberalización de servicios y reglas de origen (Solís y Katada, 2007: 1). En el caso de México este acuerdo se convirtió en el primer instrumento legal de comercio con Asia. El texto del AFAEMJ pone en evidencia el interés de nuestro país en la diversificación comercial, la apertura de nuevos mercados así como el incremento de la competitividad de los productos mexicanos. En este marco, el sector automotriz es un área muy sensible para ambos países, por lo que representa en términos de competitividad para Japón y de inversión y empleo para México. ${ }^{3}$

2. Los objetivos particulares de Japón con respecto al acuerdo son: 1) Aprovechar a México como base de exportación al mercado de los Estados Unidos, Sudamérica y Europa; utilizar la amplia red mexicana de 11 TLC con 42 países, lo cual da a México un acceso preferencial a naciones que concentran dos terceras partes del PIB mundial. 2) Resolver la dificultad e inestabilidad en la instrumentación de los Programas de Promoción Sectorial (Prosec), la Regla octava y el Aviso automático, con el fin de mejorar el ambiente de negocios. 3) Aminorar su desventaja frente a las empresas estadounidenses y europeas, las cuales ya suscribieron TLC con México, y consolidar la posición de las empresas japonesas; corregir la diferencia aduanera de $16 \%$ promedio con respecto a las empresas estadounidenses y europeas, la pérdida de oportunidad exportadora de unos 400 mil millones de yenes anuales, corregir la disminución del PIB de unos 620 mil millones de yenes anuales, la pérdida de empleos de unas 32 mil personas, y la pérdida de compras gubernamentales de la planta eléctrica por unos $120 \mathrm{mil}$ millones de yenes, entre otros. Véase Tokoro, Yasuhiro (enero, 2006), "México y Japón: una perspectiva del Acuerdo de Asociación Económica”, Economía UNAM, vol. 3, núm. 7, pp. 4768, en: http://www.ejournal.unam.mx/ecu/ecunam7/ecunam0703.pdf (recuperado el 11 de agosto de 2010).

3. Es relevante el interés que el sector empresarial japonés tuvo al presionar para concretar la firma de este acuerdo de asociación. Asimismo, organizaciones gubernamentales como JETRO advirtieron que la negociación de acuerdos comerciales brindaba la oportunidad de participar en un sistema de preferencias que los bloques económicos cerrados imposibilitaban. Desde 
En el caso japonés el AFAEMJ ha incidido positivamente al mantenerlo competitivo en los mercados que representaron a principios del siglo serios problemas para sus productos. De acuerdo con Solís y Katada, el acuerdo es

Los beneficios para

México han sido poco

representativos en

términos comerciales,

por ello resulta

imperativo utilizarlo

como un instrumento

para promover sectores

estratégicos y aprovechar

las ventajas que brinda

mantener relaciones

económicas y de

cooperación con uno de

los países más avanzados

en el mundo

un marco regulatorio en virtud de la importancia de motivos económicamente defensivos (diversificación comercial) y del avance de las negociaciones intrarregionales (por medio de la capacidad de construcción de precedentes), dado que las empresas japonesas habían reportado pérdidas importantes ante la firma del TLCAN y del Acuerdo con la Unión Europea, los intereses industriales demandaron la firma del acuerdo con México con el fin de gozar de trato preferencial como nación más favorecida (2007: 299). México, sin duda, representó para Japón un reto en la negociación de un acuerdo bilateral; lograrlo se convirtió en un punto de partida para la negociación de otros acuerdos con países asiáticos.

Si bien es cierto que el AFAEMJ tiene una importancia capital en materia de inversión y empleo, el sector empresarial mexicano ha realizado esfuerzos nimios puesto que se trabaja con un sistema productivo ineficiente. El acuerdo ha incrementado el comercio entre ambos países, pero son los japoneses quienes mayor provecho han obtenido, en

la perspectiva mexicana el acuerdo ha planteado una oportunidad para recibir inversión extranjera en el sector manufacturero, diversificando sus fuentes y promoviendo el empleo. Si vemos la inversión en el sector automotriz, encontramos que al año siguiente de la firma del acuerdo Nissan invirtió 1.3 mil millones de dólares para crear un nuevo compacto y Toyota invirtió 160 millones para expandir su primera planta ensambladora en Tijuana. De esta manera, el beneficio ha sido muy alentador para Japón. "Japón ya está tomando ventaja del acuerdo para acceder al mercado norteamericano. Las compañías automotrices están manufacturando modelos contemporáneos en México. Estos autos son más tarde comercializados en otros países de América del Norte como los Estados Unidos" (Jackson, 2006: 13). 
especial las corporaciones del ramo automotriz y electrónico. ${ }^{4}$ Los beneficios para México han sido poco representativos en términos comerciales, por ello resulta imperativo utilizarlo como un instrumento para promover sectores estratégicos y aprovechar las ventajas que brinda mantener relaciones económicas y de cooperación con uno de los países más avanzados en el mundo. ${ }^{5}$

Los objetivos de cada país mostraron en el proceso de negociación la conveniencia de la complementariedad, pues cada parte recibiría de la otra los recursos para satisfacer las necesidades internas de cada nación.

Mientras Japón recibe de México insumos, materia prima y productos alimentarios para su población, México, por su parte, se dedica a importar bienes intermedios y de capital que no se producen en el país ( $90 \%$ de las importaciones mexicanas provenientes de Japón son aceros especializados, semiconductores, paneles para televisores de plasma, entre otros de índole similar) ${ }^{6}$

4. El aumento de las exportaciones mexicanas se concentra en molibdeno, sal, plata y automóviles. Cabe señalar que los exportadores nacionales no están aprovechando todas las ventajas del acuerdo. Japón, por ejemplo, otorgó a México cupos o montos anuales de productos que pueden ser exportados sin pagar arancel y que no se están utilizando al 100\%, como sería el caso del plátano, carne de puerco, carne de bovino, artículos de piel, calzado y miel de abeja, entre otros (Vélez, 2007: 15).

5. El AFAEMJ se planteó inicialmente con los siguientes objetivos: 1) impulsar un flujo más libre de bienes, personas, servicios y capitales que cruzan la frontera entre México y Japón; 2) intensificar la asociación económica comprensiva mediante la estipulación de condiciones para la cooperación en los siguientes rubros: industria de soporte, pequeñas y medianas empresas, promoción del comercio y la inversión, ciencia y tecnología, educación y capacitación laboral, así como mejoramiento del ambiente de negocios; 3 ) construir un gran mercado armónico entre México y Japón, impulsando la reforma estructural. Bilateralmente, aprovechar al máximo la complementariedad entre las economías y promover el desarrollo económico; 4) impulsar la relación económica entre Japón y Sudamérica, y entre México y Asia. Es importante resaltar que los objetivos específicos de cada país son diferentes. En el caso de México, los objetivos están dirigidos al incremento de las exportaciones al mercado japonés, y a la atracción de mayores flujos de inversión que contribuyan a incrementar la producción, el empleo y la competitividad. Véanse Ministerio de Asuntos Exteriores de Japón (marzo de 2004), Joint Press Statement "The agreement between Japan and the United States for the strengthening of the economic partnership", en: http://www.mofa.go.jp/region/latin/mexico/joint0403. html (recuperado el 21 de octubre de 2010) y Secretaría de Economía (10 de marzo de 2004), “¿Por qué es bueno un Acuerdo de Asociación Económica (AAE) con Japón?, en: http://www. economia-snci.gob.mx/sphp_pages/sala_prensa/htm/nota_gral_aae_mex_japon_100304. htm (recuperado el 9 de agosto de 2010).

6. Centro de Estudios Asiáticos, UANL (julio-agosto de 2009), “Japón: el mayor inversor asiático en México”, en: www.uanl.mx/secciones/acerca/dependencias/cea/archivos/boletin3.pdf (recuperado el 30 de agosto de 2010). 
Hoy, a más de cinco años de la puesta en marcha del acuerdo de asociación, el comercio bilateral sí se incrementó, aunque los rubros en los que México alcanzó un beneficio real son aún limitados. De acuerdo con Melba Falck, la participación relativa de Japón en el comercio total de México disminuyó de $4.3 \%$ a $3.4 \%$ en el periodo que va de 2005 a 2008 y el incremento en el nivel del comercio entre ambas naciones estuvo más bien determinado por el crecimiento de las importaciones mexicanas procedentes de Japón (2009: 43).

Los vínculos entre México y Japón responden a una realidad más compleja: las grandes diferencias en desarrollo de ambos países los ubican como economías complementarias, no obstante las diferencias en el modo y forma de crear sus estrategias de desarrollo, las prioridades son diferentes; desde el punto de vista cultural, México requiere un avance en la formación de recursos humanos con especialización en el área de Japón, en su historia y su cultura, lo que permitirá a México entender la forma de negociar japonesa y crear estrategias adecuadas para ese modelo, considerando que todavía no se concretan los objetivos inicialmente planteados.

El incremento en la actividad comercial entre México y Japón se ubica en el aumento de las importaciones que las mismas empresas japonesas localizadas en México están haciendo de insumos de su propio país y cuyos productos finales están destinados al mercado estadounidense; esta situación, en lugar de reportar indicadores de diversificación del comercio mexicano, eleva las cifras del comercio con Estados Unidos, mercado principal de destino de los productos acabados japoneses.

La esperada diversificación de los productos mexicanos exportados a Japón no ha variado, éstos siguen concentrados en el rubro de alimentos, principalmente aguacate, atún y derivados de pescado, materias primas como aceites, minerales y esencias concentradas y productos manufacturados entre los que destacan unidades de control, unidades de memoria y placas fotográficas. De acuerdo con Falck:

[...] existe un fuerte potencial de exportación que México no ha aprovechado en el mercado nipón, especialmente en el mercado alimentario, el de vestido y el de calzado, dadas las ventajas comparativas de México. Este último aspecto ha sido el resultado de que tanto el gobierno como el sector exportador mexicano concentraron la mayor parte de su esfuerzo en aprovechar las ventajas que ofrecía el TLCAN y descuidaron otras regiones como la Unión Europea y AsiaPacífico (2009: 46). 
El acuerdo ofrece a México la oportunidad de diversificar sus exportaciones en el mercado japonés. En el sector alimentario México es competitivo en el rubro de frutas y vegetales, especialmente si consideramos los cambios en la dieta alimentaria japonesa que cada vez incluye más productos congelados o procesados. Pero México requiere incentivos para exportar productos como tomate natural o procesado, o bien aquéllos que pudiesen resultar muy competitivos en el mercado japonés, como prendas de vestir o calzado de piel —donde las industrias de León, Guanajuato, y de Guadalajara, Jalisco, han mostrado gran calidad en sus productos.

En este contexto, compartimos la convicción de que la cooperación entre ambas naciones en el mediano y largo plazo será una herramienta eficiente para impulsar el desarrollo de la tecnología, la educación y la capacitación técnica. Mediante el conocimiento y las estrategias adecuadas, México podría obtener mayores beneficios debido a que: a) el acuerdo de nueva generación brinda la oportunidad de seguir obteniendo apoyos de Japón y b) puede encontrar recursos para subsanar problemas de desarrollo a través de apoyos directos provenientes de Japón en los rubros señalados. Sin embargo, es imperativo reconocer que como país no hemos definido todavía ninguna estrategia orientada a superar nuestro atraso tecnológico con respecto a Japón.

Hasta ahora, el interés de Japón se ha focalizado en nuestro mercado interno y nuestra capacidad como proveedores de materias primas. Los proyectos en términos de cooperación, tanto tecnológica como educativa y de capacitación apoyados por la JICA y JETRO son muy específicos. La pregunta de cuán estratégica puede ser la asociación entre México y Japón puede resolverse a partir de la revisión de los indicadores básicos, ya que éstos nos permiten situar a México en una perspectiva de comparación con otros socios no sólo del propio México, sino también de Japón.

Si bien es cierto que, entre 2009 y 2010, los gobiernos de México y Japón reconocieron formalmente que uno de los puntos fundamentales en su relación bilateral es el intercambio científico y tecnológico, éste todavía tiene rango de "potencial" y no ha ido más allá de los seminarios donde participan académicos y del discurso político.

Un aspecto insoslayable a la hora de analizar lo que se señala en el AFAEMJ, es que estamos ante un acuerdo que busca fortalecer la asociación económica entre México y Japón. En los textos de divulgación reciente se ha omitido del título el término fortalecimiento. Parecería un asunto menor, pero es la clave para entender lo que ha pasado desde que entró en vigor hace cinco años. 
Tabla 1

Indicadores clave de Japón, México, República de Corea

y Estados Unidos en 2009

\begin{tabular}{|c|c|c|c|c|c|}
\hline Indicadores & EU & China & Japón & México & $\begin{array}{c}\text { Rep. de } \\
\text { Corea }\end{array}$ \\
\hline Población (millones de habitantes) & 314.7 & $1,345.8$ & 127.2 & 109.6 & 48.3 \\
\hline $\begin{array}{l}\text { PIB (en miles de millones de dólares } \\
\text { estadounidenses) }\end{array}$ & $14,256.3$ & 4,909 & $5,068.1$ & 874.9 & 832.5 \\
\hline PIB per cápita (en dólares estadounidenses) & 46,381 & 3,678 & 39,731 & 8,135 & 17,074 \\
\hline $\begin{array}{l}\text { PIB (PPA) como parte porcentual del total } \\
\text { mundial }\end{array}$ & 20.46 & 12.52 & 6.00 & 2.09 & 1.94 \\
\hline
\end{tabular}

Fuente: Foro Económico Mundial. Reporte de Competitividad Global 2010-2011.

La primera pregunta es: ¿Qué quiere México de este acuerdo? Básicamente, promover el comercio y la inversión, así como lograr un acceso preferencial al mercado japonés. El supuesto fundamental es que las exportaciones al mercado japonés y la atracción de flujos mayores de inversión incidirían en el aumento de la producción, el empleo y la competitividad. Sin embargo, trabajar con uno de los países más competitivos del mundo global es un reto. En el Reporte global de competitividad 2010-2011 Japón aparece posicionado en el lugar número 6, mientras que México lo está en el lugar número 66, cayó seis sitios con respecto al reporte de 2009-2010. El único aspecto en el que nuestro país supera a Japón es en el ambiente macroeconómico.

Así, si bien es un hecho que el AFAEMJ en su diseño es ante todo un tratado de libre comercio, también es un instrumento promotor de la cooperación bilateral en: industria de soporte, pymes, comercio e inversión, ciencia y tecnología, educación y capacitación laboral, turismo, agricultura, propiedad intelectual, medio ambiente y mejoramiento del ambiente de negocios. Tomando en consideración la relevancia que el tema de la cooperación tiene en el marco de este acuerdo de asociación, en nuestro trabajo proponemos el análisis de las disposiciones relativas a la cooperación económica bilateral contenidas en el AFAEMJ que en teoría permitirán aprovechar de mejor manera la liberalización y apertura de los mercados de bienes, servicios y capitales entre los dos países, pero que representa también un instrumento para que Japón alcance sus metas comerciales. Entonces, surge la segunda pregunta: ¿Cuáles son las disposiciones que permitirán a dos países tan disímbolos 
Tabla 2

Competitividad de México, Japón, EU, China

y la República de Corea, 2009-2010

\begin{tabular}{|c|c|c|c|c|c|c|c|c|c|c|c|c|c|}
\hline País & $\begin{array}{l}\overrightarrow{8} \\
\frac{0}{0} \\
0 \\
0 \\
0 \\
\tilde{0} \\
\approx \\
2\end{array}$ & 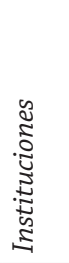 & 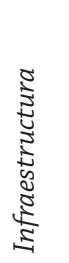 & 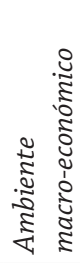 & 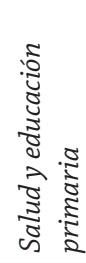 & 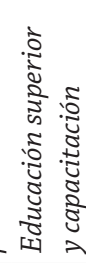 & 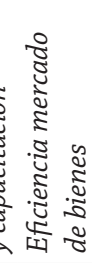 & 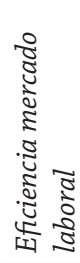 & 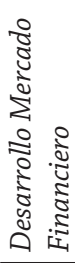 & 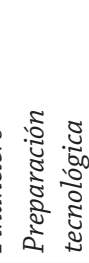 & 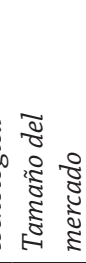 & 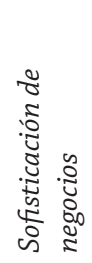 & 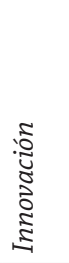 \\
\hline EU & 4 & 40 & 15 & 87 & 42 & 9 & 26 & 4 & 31 & 17 & 1 & 8 & 1 \\
\hline China & 27 & 49 & 50 & 4 & 37 & 60 & 43 & 38 & 57 & 78 & 2 & 41 & 26 \\
\hline Japón & 6 & 25 & 11 & 105 & 9 & 20 & 17 & 13 & 39 & 28 & 3 & 1 & 4 \\
\hline México & 66 & 106 & 75 & 27 & 70 & 79 & 96 & 120 & 96 & 70 & 12 & 67 & 78 \\
\hline $\begin{array}{l}\text { Rep. de } \\
\text { Corea }\end{array}$ & 22 & 62 & 18 & 6 & 21 & 15 & 38 & 78 & 83 & 19 & 11 & 24 & 12 \\
\hline
\end{tabular}

Fuente: elaboración propia con base en las tablas 6, 7 y 8 del Reporte de Competitividad Global 2010-2011.

promover el fortalecimiento de sus relaciones de cooperación en materia de tecnología, educación y capacitación técnica?

Si bien el intercambio comercial entre Japón y México no ha sido aprovechado del todo empleando los mecanismos ofrecidos por AFAEMJ, hay otros aspectos de este acuerdo que han sido prácticamente ignorados, por no estar vinculados directamente con la obtención de beneficio económico, que es el objetivo principal del AFAEMJ. Estos aspectos están conectados con la realización de esfuerzos bilaterales encaminados a la protección del medio ambiente global, utilizando para ello tanto los mecanismos de desarrollo limpio, como la transferencia de tecnología para el uso eficiente de energía y el aprovechamiento de las fuentes renovables de energía, área en la cual Japón es uno de los países con mayor avance.

¿Cuál es la razón por la que México y Japón no han sumado esfuerzos en estas cuestiones que pudieran generar tanto beneficios económicos para ambas naciones, como contribuir de manera indiscutible a la preservación del medio ambiente global? Al realizar un análisis preliminar de estos dos países podemos percatarnos de que Japón y México no se encuentran en condiciones energéticas similares. Si bien México por el momento es un país exportador neto de energía (en la forma de hidrocarburos y electricidad), Japón ha sido 
desde siempre un país muy pobre en recursos energéticos propios, por lo que se ha visto en la necesidad constante de importarlos y de realizar esfuerzos para alcanzar un cierto grado de independencia energética.

Entonces, las prioridades en materia energética son diferentes en ambos países. No obstante, la firma de protocolos internacionales que establecen metas de reducción de emisiones y un incremento de la participación de fuentes de energía renovable en el suministro total de energía primaria han contribuido a cierta unificación de los objetivos del desarrollo del sector energético.

Hasta el momento, el desarrollo de la tecnología de aprovechamiento de las energías renovables en México ha dependido principalmente de su país vecino del norte (desarrollos académicos y aplicaciones prácticas en comunidades aisladas del suministro eléctrico convencional) y de España (inversiones directas, por ejemplo en el proyecto del parque eólico del Istmo de Tehuantepec, en Oaxaca). Los casos de la participación de Japón en el mercado de energías renovables en México son todavía aislados, siendo la producción de paneles solares su fuerza principal en nuestro país. Entonces, como veremos más adelante, el lento avance de la cooperación entre México y Japón en este rubro del AFAEMJ se debe principalmente a la política exterior de Japón, que pone a la cabeza el beneficio económico para sus empresas, y a la pasividad de México en el tratamiento de cuestiones ambientales y de cooperación con la nación asiática.

Otro de los problemas que enfrenta México en materia de competitividad en el comercio exterior es la falta de articulación de las cadenas productivas en donde la participación de las micro, pequeñas y medianas empresas (pymes) pueden hacer más eficientes a las empresas exportadoras o crear cadenas de exportación. El rubro de cooperación contenido en el AFAEMJ incluye un apartado destinado a brindar apoyos para promover a las pequeñas y medianas industrias.

A partir de la firma del acuerdo se estableció el Comité para el Mejoramiento del Ambiente de Negocios y se creó el proyecto de formación y entrenamiento para recursos humanos que asesoren pymes. Estos programas tienen como fin impulsar a las pymes mexicanas e incluirlas en los procesos productivos, poniendo especial atención en el sector automotriz. La mención de este sector en el acuerdo es relevante y pudiese abrir una opción para México.

En el acuerdo se aclara que las pymes deben articularse en la cadena productiva de manera que el desempeño de la industria mexicana sea más eficiente. En el artículo 141 del AFAEMJ se establece la cooperación en materia 
de pymes como medio para mantener el dinamismo de las economías de Japón y México y promover un ambiente favorable para el comercio y la inversión bilateral. Esta cooperación podrá incluir: (a) intercambio de información sobre políticas para las pymes para: (i) fortalecer la competitividad de las pymes, (ii) asistir a las PYMES para iniciar negocios y (iii) promover redes empresariales de las pymes; (b) fomento al establecimiento de redes entre entidades apropiadas de ambas partes que proporcionen asistencia a las pymes y (c) fomento al intercambio de expertos en el desarrollo de las pymes. ${ }^{7}$

Considerando que en este trabajo proponemos la revisión del AFAEMJ desde su apartado de la cooperación, empleamos algunos conceptos del enfoque realista para delimitar el marco de referencia a partir del cual entendemos la cooperación en el caso japonés.

En el caso que desarrollamos, nos parece pertinente el análisis del tema de cooperación que ha sido incluido en el AfAEmJ y que brinda a México, como mencionamos, la oportunidad de tener acceso a ciertos beneficios en los programas de cooperación económica de Japón. Para resaltar las ventajas y debilidades que, en el marco de la cooperación, han tenido los sectores que analizamos aquí, es necesario un planteamiento, al menos general, del tema de cooperación, enfocándolo desde la perspectiva del realismo político, mencionando a autores tales como David Arase, Kasuji Nagazu, Alan Rix y Tadashi Yamamoto, que se han dado a la tarea de trabajar el tema de cooperación japonesa. Lo anterior nos permitirá tener una idea de los intereses entrelazados en la firma del acuerdo.

Desde las condiciones particulares de Japón, el tema de la cooperación se justifica en el marco de sus estrategias de aseguramiento de mercados y materias primas y podemos analizarlo desde diferentes ópticas.

Desde la perspectiva económica, si la cooperación puede asegurar cambios en las instituciones de los países con quienes coopera y estos cambios, a su vez, promueven la productividad de la economía, el bienestar de la población y la igualdad en la distribución del ingreso, con ello se asegura la estabilidad económica propicia, tanto para mantener un proveedor de recursos útiles para sus programas de desarrollo industrial, como para tener un mercado para sus productos. Rosenstein-Rodan argumentan que, en términos generales, la racionalidad económica surge del interés por incrementar la eficiencia de las economías en desarrollo y promover la economía global (1970).

7. Véase texto del AAEMJ, p. 84. 
Desde la perspectiva política, la cooperación es un instrumento de las relaciones internacionales para ganar concesiones políticas de un gobierno que tiene valor estratégico para el país más desarrollado.

En este sentido, la perspectiva del realismo clásico nos sirve para analizar la importancia del aspecto económico de la estrategia japonesa y el uso de diversos instrumentos para conservar o consolidar su posición económica en el mundo. Este enfoque teórico nos permite distinguir los intereses que median en la inclusión de un apartado referente a la cooperación en el acuerdo. El interés japonés puede ser ubicado en una estrategia empresarial que permitió, desde los sectores más relevantes, sentar las condiciones para una mejor inserción en el mercado estadounidense o bien justificar actividades comerciales en el marco de sistemas de colaboración en áreas sensibles, tal es el caso de la protección del medio ambiente.

En el marco del AFAEMJ podemos encontrar que si bien la inclusión del tema de cooperación hace de este acuerdo un instrumento innovador - $\mathrm{o}$ como le llaman, un acuerdo de nueva generación-, permitiéndole a un país como México continuar aprovechando las ventajas de colaboración con un país altamente industrializado, también lo es que la política de cooperación japonesa ha servido de herramienta para perpetuar una relación asimétrica entre países receptores y donadores. México tiene un lugar especial en los planes japoneses. El acceso a los recursos naturales, a los mercados de consumidores en constante expansión y la consolidación de una base de producción para la exportación hacia el mercado de Estados Unidos, así como el desarrollo de economías regionales unificadas como el TLCAN o Mercosur, que crean una oportunidad para la inversión japonesa.

Japón resume las oportunidades de negocios que brinda México en tres puntos: es importante y prioritario por ser integrante del TLCAN, México forma parte de la región geográfica de la Cuenca del Pacífico y es una nación latinoamericana con importantes recursos, especialmente el petróleo (Donovan y Kim, 2002: 28; véase también Altbach, 1998). De manera que encontramos que uno de los motivos que han promovido la participación japonesa en América Latina, y especialmente en México, es la formación y consolidación de una base de exportaciones para que sus productos tengan acceso a diferentes mercados especialmente el de Estados Unidos.

El TLCAN se ha convertido en un incentivo importante para la cooperación con Japón. El objetivo de ser cada vez más competitivo en el mercado internacional lleva a Japón a implementar estrategias que les permita obtener 
componentes a bajo costo. Japón ha comprometido recursos para apoyar programas de recuperación de industrias mexicanas que fabriquen partes a bajo costo necesarias en el proceso productivo de las empresas japonesas.

Kazuji Nagasu (1970) planteaba que la concepción japonesa de asistencia (enjo), ya desde los años setenta del siglo xx ha estado atada a la expansión del mercado y a la procuración de recursos para la industria japonesa. Por su parte, Alan Rix (1980) aseguraba que las decisiones en torno a la cooperación se explican por una combinación de los modelos políticos, las organizaciones y las instituciones gubernamentales, argumenta que el principal determinante de la política japonesa de cooperación y en particular de la asistencia son los intereses burocráticos, hoy sumados a los intereses de la clase empresarial. En este sentido, si consideramos la postura de Yamamoto (1978) en torno a la cooperación y a la asistencia japonesa, tenemos que el principio que rige esta política es la iniciativa empresarial, entendiendo la cooperación como un instrumento que crea las condiciones para que el capital japonés encuentre un ambiente propicio. David Arase (1995), plantea que la cooperación japonesa requiere de un estudio que explique cómo el interés económico interno se vincula con los actores burocráticos de la política y el Estado para diseñar e implementar esa estrategia. Los intereses económicos y políticos son tan importantes como los intereses diplomáticos y de seguridad en Japón.

Dada la relevancia del apartado de cooperación, en este trabajo, consideramos como objeto de análisis: a) tecnología, educación y capacitación técnica; b) medio ambiente y energía; c) pequeñas y medianas empresas, en el supuesto de que si bien no son los únicos en el acuerdo, sí nos parecen los más relevantes de atender.

\section{a) Tecnología, educación y capacitación técnica}

Las disposiciones que permitirán a dos países tan disímbolos como México y Japón promover el fortalecimiento de sus relaciones de cooperación están contenidas en el capítulo 14 del texto del AFAEMJ en donde se señala en los artículos 142 y 143, la naturaleza de la cooperación en materia de ciencia y tecnología, de educación técnica, vocacional y capacitación, respectivamente.

En el artículo 142 se señala que tanto México como Japón reconocen que la ciencia y la tecnología contribuirán al continuo desarrollo de sus respectivas economías en el mediano y largo plazo, y por ello, los gobiernos de ambos países desarrollarán y promoverán actividades de cooperación en materia 
de ciencia y tecnología con propósitos pacíficos sobre bases de equidad y beneficio mutuo. Entre las modalidades de las actividades de cooperación se consideraron: ${ }^{8}$

a) Intercambio de información relativa a políticas y programas y datos de ciencia y tecnología.

b) Seminarios, talleres y reuniones conjuntas.

c) Visitas e intercambios de científicos, personal técnico u otros expertos.

d) Implementación de proyectos y programas conjuntos.

e) Fomento a la cooperación para la investigación y desarrollo relacionados con tecnologías de aplicación industrial.

f) Fomento a la cooperación entre instituciones educativas y de investigación.

En lo que respecta a cooperación en materia de educación técnica, vocacional y capacitación, el artículo 143 puntualiza que México y Japón, reconociendo que el crecimiento económico sostenible y la prosperidad dependen en gran medida del conocimiento y las habilidades de las personas, desarrollarán la cooperación entre sus gobiernos en materia de educación técnica y vocacional y capacitación con el objeto de elevar la productividad y competitividad de las empresas privadas de cualquiera de los dos países. Esta cooperación sobre educación técnica y vocacional y capacitación podría incluir intercambio de información relativa a mejores prácticas, incluyendo política laboral, fomento a la capacitación de instructores y el desarrollo de programas de capacitación, particularmente para el desarrollo de educación tecnológica superior y educación a distancia, así como al intercambio de especialistas, maestros, instructores y estudiantes.

De lo anterior podemos sacar en claro que si bien es cierto que la "buena voluntad" es recíproca, también lo es el que no se señala ningún mecanismo que "obligue" o "coaccione" a las partes para que efectivamente cooperen entre sí. Es relevante puntualizar que en el caso de México, éste ha desaprovechado las oportunidades históricas que ha tenido para obligar a países como Japón a transferirle tecnología avanzada. Nuestro país ha sido proveedor de materias

8. En el texto del AFAEMJ se advierte que la información científica y tecnológica que no implique derechos de propiedad intelectual derivada de las actividades de cooperación conforme al artículo 142 podrá hacerse del conocimiento público por el gobierno de cualquiera de las partes. 
primas y mano de obra barata. Japón, un productor de bienes manufacturados de alto valor agregado, no ha se tomado demasiadas molestias para transferir tecnología y capacitar a la mano de obra de un potencial competidor ubicado justo al sur de la frontera de los Estados Unidos. Asimismo, es pertinente señalar que los esfuerzos de intercambio científico y de cooperación académica no son contundentes en México dado que los intelectuales y los investigadores de todas las áreas del conocimiento tienen escasa influencia en la política pública.

Por si esto fuera poco, el presupuesto nimio que el gobierno federal destina a los rubros de la ciencia y la tecnología desdicen sus buenos deseos. En un artículo periodístico de 2007, René Drucker, científico mexicano, señaló que en México hay un científico por cada 8 mil 660 habitantes, aproximadamente. En Estados Unidos hay un científico por cada 237 habitantes, en Francia un científico por cada 184 habitantes, y en Brasil un científico por cada 2 mil 237 habitantes. Además, Brasil ya estaba invirtiendo casi $1 \%$ de su PIB en ciencia. ${ }^{9}$ En los últimos 30 años México ha destinado entre $0.3 \%$ y $0.4 \%$ del PIB a la ciencia y la tecnología. En el siguiente cuadro podemos ver nuestra realidad y compararla con la de nuestro socio asiático.

\section{Tabla 3}

Gasto interno bruto en investigación y desarrollo como porcentaje del PIB en Suecia, Japón, Estados Unidos, República de Corea y México, 2001-2008

\begin{tabular}{lcccccccc}
\hline & 2001 & 2002 & 2003 & 2004 & 2005 & 2006 & 2007 & 2008 \\
\hline Suecia & 4.17 & S/D & 3.85 & 3.62 & 3.60 & 3.74 & 3.61 & 3.75 \\
Japón & 3.12 & 3.17 & 3.20 & 3.17 & 3.32 & 3.41 & 3.44 & 3.42 \\
EU & 2.72 & 2.62 & 2.61 & 2.54 & 2.57 & 2.61 & 2.66 & 2.77 \\
Rep. de Corea & 2.47 & 2.40 & 2.49 & 2.68 & 2.79 & 3.01 & 3.21 & 3.37 \\
México & 0.36 & 0.40 & 0.40 & 0.40 & 0.41 & 0.39 & 0.38 & S/D \\
\hline
\end{tabular}

Fuente: OECD. Science and Technology: Key tables from OECD.

Mientras Japón se ubica entre los primeros cinco lugares de los países miembros de la OECD que invierten en investigación y desarrollo, el nuestro se localiza en el último. La disparidad del nivel científico-tecnológico no es el

9. Drucker Colín, René, "La ciencia no tiene quien la defienda", La Jornada. 18 de enero de 2007, en: http://www.jornada.unam.mx/2007/01/18/index.php?section=opinion\&article=022a2p ol (recuperado el 16 de octubre de 2010). 
mayor de los problemas en las relaciones México-Japón. En los últimos años, Japón ha buscado a través de la vía diplomática fortalecer sus relaciones con los países del Este de Asia, particularmente, le interesa consolidar sus vínculos con China y Corea del Sur. ${ }^{10}$

No obstante que el foco de interés está localizado en esos países asiáticos, y no en México, hace dos años el embajador Ono puntualizó ante el Senado los aspectos en los que México tendría que trabajar para atraer la inversión japonesa. Es oportuno remarcar que en esa ocasión una vez más se hizo evidente que es el comercio y no la cooperación lo que les interesa. El embajador celebró la eliminación de aranceles de $91 \%$ de las fracciones arancelarias de Japón, el incremento del comercio en $75 \%$, el crecimiento de las exportaciones mexicanas de atún, pulpo y café y la triplicación de la inversión de 2004 a 2005 en los sectores automotriz y electrodoméstico. ${ }^{11}$ Instaba a México a competir por la atracción de capitales, esos "capitales sin frontera", y para lograr el éxito tanto en esta tarea como en la mejora del ambiente de negocios y la competitividad dictó cinco recomendaciones que, si se analizarán una por una, darían para un ensayo extenso. ${ }^{12}$

Sabemos que los problemas de México no están en su sistema financiero sino en su capacidad para enfrentar los retos que le plantea este tipo de

10. Japón estableció un acuerdo para promover la cooperación con miras al desarrollo futuro de la región en el marco de la Primera Cumbre Trilateral Japón-China-República de Corea celebrada en Fukuoka, Japón en diciembre de 2008. Véase: “Orientación básica de la política exterior del Japón”. Discurso del Ministro de Relaciones Exteriores Hirofumi Nakasone sobre la Política General ante la 171 sesión de la Dieta. 28 de enero, 2009, en: http://www.minem. gob.pe/minem/archivos/file/institucional/publicaciones/presentaciones/discurso_japon_2. pdf (recuperado el 29 de agosto de 2010).

11. Véase el discurso del embajador Ono en la Cámara de Senadores. Mensaje del embajador Masaaki Ono en el Foro-Taller sobre el Acuerdo de Asociación Económica entre Japón-México, mayo de 2008, en: http://www.mx.emb-japan.go.jp/sp/mensaje.html (recuperado el 18 de octubre de 2010).

12. Los cinco puntos son: 1) Protección de la propiedad intelectual, ya que a pesar de los esfuerzos realizados hasta ahora, todavía el problema de la "piratería" está latente. 2) Estabilidad en el sistema recaudatorio, puesto que es muy difícil planificar las actividades económicas a largo plazo bajo una situación en donde el sistema de impuestos sufre cambios con frecuencia. 3) Mejora en la seguridad, ya que los secuestros de los empresarios y robos de mercancías durante el transporte son una preocupación permanente de las empresas en México. 4) Flexibilidad en los asuntos laborales: la falta de flexibilidad de la ley laboral y la fuerza excesiva de los sindicatos dañan a la competitividad en algunos casos. 5) Fomento a las pymes y a la industria de soporte porque las empresas japonesas establecidas en México necesitan encontrar proveedores mexicanos que puedan venderles las partes y componentes que necesitan para trabajar. 
asociación; el más grande es el de la educación y la capacitación técnica. Es imperativo elevar la calidad educativa y el acceso a la educación terciaria pues en el largo plazo esto se convierte en un requisito para el crecimiento económico. Tenemos la convicción de que un sistema educativo solvente en el caso mexicano tendría un impacto profundo de naturaleza positiva en los niveles de empleo. En la actualidad, otro de los retos que enfrentamos es el de abatir las tasas de desempleo que se han agudizado por la crisis global de 2009.

A principios de 2010, tras la conclusión del Foro Económico Mundial, el presidente Felipe Calderón realizó una visita oficial a Japón para promover la inversión japonesa en los sectores automotriz, autopartes, electrónico, energías limpias, ahorro energético e infraestructura. En el marco de esa visita volvió a hacer alusión a la necesidad de profundizar en la relación de cooperación y conmemorar los 400 años de contacto amistoso. En esa ocasión se reunió con el otrora Primer Ministro Yukio Hatoyama y se entrevistó con mandos directivos de Toyota. El primer ministro Hatoyama le ofreció capacitación para mejorar la seguridad pública en México, pues garantizar la seguridad de las empresas niponas se ha convertido en un requisito para que vengan a invertir.

El detentor del Poder Ejecutivo del gobierno mexicano ha ido afirmando por el mundo que continuarán las reformas para mejorar la competitividad del país. Aunque dijo que México cuenta con una mano de obra joven bien preparada que se ha convertido en el atractivo para invertir de algunas corporaciones, se sabe - $y$ ha sido señalado por personajes enterados como el rector de la UNAM, José Narro Robles - que prevalece en nuestro país el analfabetismo, el rezago educativo y que urge doblar la cobertura de educación superior. El secretario general de la OCDE, José Ángel Gurría urgió a nuestro país a mejorar la calidad de las escuelas e invertir en educación, porque de esa manera se invierte en el futuro. No debemos soslayar el impacto negativo que tuvo la crisis en la economía; se promueve la inversión en infraestructura, pero todavía no son visibles los proyectos estratégicos que van a transformar nuestro país.

Una de las decisiones más importantes tomadas por el presidente Calderón y el primer ministro Hatoyama fue la firma del Plan de Acción para la Asociación Estratégica Global entre México y Japón, que incluye el impulso de proyectos de cooperación hacia terceros países en forma conjunta. Este nuevo plan tiene su antecedente en el documento Asociación Estratégica del Pacífico: México-Japón en el nuevo milenio, firmado por los ex mandatarios Vicente Fox y Junichiro Koizumi en 2003. En opinión de Calderón, este plan de acción conjunto no se circunscribe únicamente a los objetivos para 
impulsar la economía mundial sino también incluye aspectos fundamentales como las medidas para enfrentar el cambio climático, promover el desarme y la no proliferación de armas nucleares para buscar la paz y la seguridad mundial, respetando plenamente los derechos humanos. Asimismo, reiteran su cooperación como miembros no permanentes del Consejo de Seguridad de la Organización de las Naciones Unidas. ${ }^{13}$

Otro resultado de la mencionada visita el $1^{\circ}$ de febrero de 2010, fue la firma de un convenio de cooperación para facilitar el intercambio de investigadores y la realización de proyectos y seminarios conjuntos. Éste se celebró entre el Consejo Nacional de Ciencia y Tecnología (Conacyt), representado por Juan Carlos Romero Hicks, y la Agencia de Ciencia y Tecnología de Japón, encabezada por Koichi Kitazawa. Durante la visita se puso de manifiesto un interés por los temas de energía y el cambio climático, por lo que sus respectivos ministros de relaciones exteriores se comprometieron a estrechar la cooperación para lograr el éxito de la Cumbre sobre Cambio Climático de las Naciones Unidas (COP 16), celebrada en México a finales de 2010.

\section{b) Medio ambiente y energía}

Ya en el texto del acuerdo firmado, en el artículo 147, se mencionan las modalidades generales que orientan a la cooperación bilateral para la preservación y el manejo sustentable de los recursos naturales con los que cuentan México y Japón. ${ }^{14}$ ¿Cómo se han ido cumpliendo estos puntos del acuerdo? ¿Cómo se ha dado la cooperación entre México y Japón en materia del cuidado del medio ambiente dentro y fuera del marco del acuerdo económico mutuo?

$\mathrm{Si}$ analizamos de manera general los logros obtenidos en el área, podemos darnos cuenta de que éstos no han ido mucho más lejos que los logros económicos del acuerdo, por no decir que son mucho más tenues. ¿Cuál es la razón por la que no se ha aprovechado debidamente esta parte del acuerdo?

Observemos la situación en el caso del aprovechamiento de las fuentes de energía renovables — uno de los componentes principales de la estrategia

13. En teoría este plan de acción permitirá canalizar apoyos y responder a los daños del terremoto en Haití, solventar proyectos de integración y desarrollo en Mesoamérica y sustentar la Agencia de Cooperación Internacional para el Desarrollo.

14. Sistema de Información sobre Comercio Exterior (SICE) de la Organización de los Estados Americanos. Acuerdo de Asociación Económica México-Japón, en: http://www.sice.oas.org/ Trade/MEX_JPN_s/JPN_MEXind_s.asp (recuperado en octubre de 2010). 
global para la mitigación del cambio climático y la preservación de los recursos naturales-. México y Japón son países muy distintos en sus patrones de producción y consumo de energía. México era, y hasta el momento sigue siendo, un productor y exportador neto de energía (principalmente en forma de petróleo crudo y electricidad). Por su parte, Japón, desde el inicio de su desarrollo industrial, ha sido un importador neto de energía por la ausencia casi completa de fuentes propias.

La altísima dependencia de las importaciones de petróleo del Medio Oriente se mantuvo hasta la primera crisis petrolera, en 1973, que obligó al país asiático a revisar seriamente su política energética con el fin de disminuir su dependencia del petróleo crudo como principal fuente de abastecimiento energético. Fue precisamente a partir de ese momento que Japón decide reforzar su seguridad energética a través de la diversificación de las fuentes de energía, el establecimiento de ciclos energéticos domésticos (enfatizando la energía nuclear como la fuente con mayor potencial para alcanzar este objetivo), y mediante el ahorro y uso eficiente de los recursos energéticos disponibles.

Pudiéramos, por lo tanto, suponer que si la ampliación del uso de energías renovables en Japón era casi una necesidad imperiosa para alcanzar la seguridad energética, en el caso de México, donde contamos con abundantes recursos fósiles de energía (petróleo, gas natural, carbón) de un costo relativamente bajo, no existe la necesidad de desarrollar esta industria. No obstante, hacer esta suposición para explicar el lento avance de la cooperación entre México y Japón en materia del cuidado del medio ambiente mediante el aprovechamiento de fuentes renovables de energía implicaría caer en una simplificación irresponsable de una situación mucho más complicada y poco factible de ser analizada en este trabajo.

La integración misma de objetivos de carácter ambientalista en acuerdos que persiguen la obtención de beneficios económicos ha sido materia de controversia no sólo en el caso de México, sino también para prácticamente todos los países de América Latina. En un estudio de la CEPAL fueron resumidas algunas razones por las cuales las evaluaciones de los efectos de los tratados de comercio sobre el medio ambiente no están explícitamente incluidas. ${ }^{15}$

15. Véase De Miguel, Carlos J. (junio 1-2, 2010), “Experience with ex-ante impact assessments and lessons learned", OECD Workshop on Regional trade agreements and the environment: monitoring implementation and assessing impacts, París, Francia, en: http://www.oecd.org/dataoecd/18/33/45548090.pdf (recuperado el 21 de octubre). 


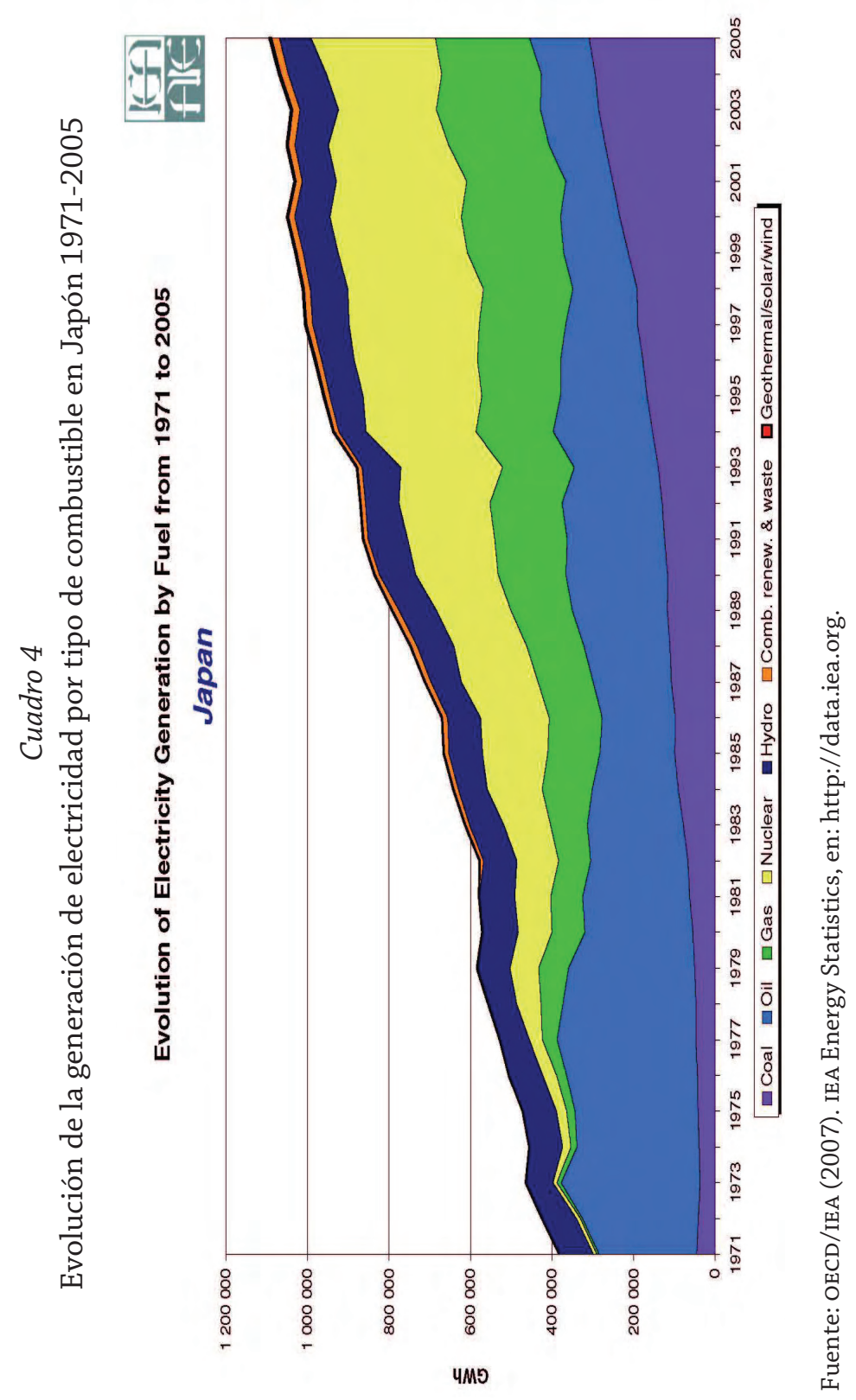


Algunas de estas razones son las siguientes: no existe una obligación de las partes firmantes para incluir aspectos de la protección del medio ambiente dentro de los tratados económicos, complejidad de los detalles de los análisis técnicos y metodológicos, la dificultad para la obtención de financiamiento para la realización de trabajos empíricos, así como la falta de información, estadísticas e indicadores que permitan tomar decisiones.

Estos puntos son aplicables a las evaluaciones de impacto ambiental de los tratados de libre comercio de países de América Latina, caso que no es precisamente el del acuerdo firmado entre México y Japón, que implica una cooperación más allá de la simple prevención y erradicación de posibles impactos ambientales del acuerdo. Empero, los puntos mencionados también pueden servir para darnos una idea de por qué falla la cooperación en la cuestión ambiental. Podemos especular que la integración del tema ambiental dentro del acuerdo fue, más bien, una especie de tributo a las tendencias globales de combate al cambio climático, reforzadas a inicios del nuevo siglo. Sin embargo, incluso el cumplimiento de estos puntos "de buena voluntad" del acuerdo se ve afectado por otras razones de peso, que examinaremos un poco más adelante.

Regresando al tema de los patrones de la generación y el consumo de energía, es necesario mencionar que están siendo modificados, por una parte, por los acuerdos internacionales encaminados a la reducción de emisiones de gases de efecto invernadero. Estos esfuerzos alcanzaron por primera vez el nivel mundial durante la conferencia de Estocolmo, en 1972. Específicamente, son el Protocolo Marco de las Naciones Unidas (1992) y la Convención-Marco de las Naciones Unidas sobre el Cambio Climático (CMNUCC), adoptada durante la conferencia de Río de Janeiro, en el mismo año, los que establecen la necesidad del alcance de objetivos de reducción de gases de efecto invernadero. La firma voluntaria del Protocolo de Kioto, derivado de la CMNUCC, por parte de México significó la aceptación de las metas de reducción de emisiones de gases de efecto invernadero. De esta manera México, a pesar de ser un país productor y exportador de recursos energéticos fósiles, toma conciencia de la necesidad de un cambio en su canasta energética hacia el uso de fuentes de energía con un menor impacto ambiental.

Por otra parte, los recursos energéticos fósiles no son inagotables y se espera que a mediano plazo México deje de ser un exportador de petróleo crudo y éste sea destinado a satisfacer los requerimientos energéticos internos del país (según las estadísticas de Pemex, las reservas de México alcanzan para 10-30 años según el tipo que se tome en cuenta para realizar el cálculo — pro- 
badas, probables y posibles). ${ }^{16}$ Desde este punto de vista, la diversificación de las fuentes de energía y la seguridad energética están comenzando a ser temas de actualidad para nuestro país.

Otro eje que articula el movimiento hacia la diversificación del suministro energético y que se encuentra plasmado en el Plan Nacional de Desarrollo hasta el 2012 es la iniciativa del gobierno federal de México de procurar el desarrollo económico dentro de un marco de sustentabilidad ambiental. ${ }^{17}$

Finalmente, la aprobación de la legislación respectiva al aprovechamiento de las energías renovables ha sido otro paso importante en el allanamiento del camino a la expansión del uso de las energías renovables en México.

En referencia al tema que nos ocupa es necesario señalar que Japón prácticamente no ha participado en este proceso de reforzamiento de la industria de las energías renovables en México, observado esto principalmente a partir de 2005. Ello se debe, al igual que en el caso del comercio, a una orientación preferencial hacia nuestro vecino del Norte.

En cooperación con los Estados Unidos, específicamente con la National Renewable Energy Laboratory, del US DOE (Departamento de Energía de EU), fueron realizados: 1) el mapeo del potencial eólico existente en la zona del Istmo de Tehuantepec, Oaxaca, 2) la evaluación del recurso solar de los estados sureños de México, 3) la promoción de las compañías de servicios de energía (ESCO, por sus siglas en inglés), 4) la implementación del Programa Mexicano de Electrificación Rural, en conjunto con la Secretaría de Energía (Sener), consistente en el uso de dispositivos aprovechadores de energías renovables para el abastecimiento eléctrico de comunidades aisladas del suministro eléctrico convencional, 5) la edición de manuales en español sobre el uso y aplicaciones de las energías renovables para escuelas, clínicas rurales y pequeñas empresas. ${ }^{18}$

La escasa importancia que tiene Japón en el desarrollo de la industria del aprovechamiento de las energías renovables en México se puede observar también por su reducida presencia en las licitaciones para la construcción de obras

16. Pemex (2009), "Reservas de hidrocarburos al 1 de enero de 2010", Memoria de Labores 2009, pp. 77-86, en: http://www.pemex.com/files/content/4_MLab_2009.pdf (recuperado en octubre de 2010).

17. Presidencia de la República (2007), Plan Nacional de Desarrollo, en: http://pnd.presidencia. gob.mx/ (recuperado en septiembre de 2010).

18. Agencia estadounidense para el desarrollo internacional (USAID) (2005), "Advancing Clean Energy Use in Mexico", en: http://pdf.usaid.gov/pdf_docs/PDACG052.pdf (recuperado en octubre de 2010). 
públicas financiadas, convocadas por la Comisión Federal de Electricidad (CFE) y la Sener como parte del proceso de apertura del mercado de las energía renovables a la inversión privada. Por ejemplo, a pesar de que la Mitsubishi Heavy Industries tiene una producción a gran escala de aspas para generadores eólicos en Ciudad Juárez, tanto los participantes en la licitación para llevar a cabo el proyecto eólico La Venta II, como la compañía que se adjudicó este contrato fueron de origen español. Exactamente lo mismo ocurre en este preciso momento con la licitación para la construcción del campo solar Agua Prieta II, en el que participan nueve compañías, de las cuales ninguna es de origen japonés. ${ }^{19}$

La participación de Japón en el establecimiento de mecanismos de protección del medio ambiente se hace aún más evidente si se analizan los proyectos constituidos dentro del Mecanismo de Desarrollo Limpio (MDL), donde México figura como país subdesarrollado. Los países incluidos en el "Anexo I" pueden financiar obras con el fin de reducir las emisiones de dióxido de carbono. A pesar de las muchas controversias que ha provocado el establecimiento de este llamado "mercado de bonos de carbono", es prácticamente uno de los pocos mecanismos que llevan al alcance de las metas de reducción de las emisiones dentro del sistema económico mundial actual. De los 134 proyectos del MDL en los que México figura como beneficiario, tan sólo tres son promovidos por Japón, y de estos sólo uno está vinculado a las energías renovables (un proyecto de producción de biogás en Ciudad Juárez). ${ }^{20}$

La participación de Japón en el desarrollo de las energías renovables en México está ilustrada en el sitio oficial de la Secretaría de Economía dedicado al Acuerdo de Asociación Económica entre México y Japón. Estos ejemplos son cinco: las compañías productoras de módulos solares Sanyo Electric en Monterrey, Kyocera en Tijuana, Mitsubishi Heavy Industries con la producción de aspas para generadores eólicos en Ciudad Juárez, y dos compañías que participan en proyectos de tratamiento de agua en varios estados de la República —Mitsui\& Co. y Sumitomo Corporation-.${ }^{21}$ La producción de

19. Comisión Federal de Electricidad (CFE), Licitación para el primer campo solar (Agua Prieta), en: http://www.cfe.gob.mx/proveedores/licitaciones/Paginas/Licitaciondelprimercamposolar.aspx (recuperado en octubre de 2010).

20. Convención Marco sobre Cambio Climático de las Naciones Unidas (CMNUCc), en: http:// cdm.unfccc.int/Projects/projsearch.html (recuperado en octubre de 2010).

21. Secretaría de Economía, oficina de representación en Japón (enero de 2010), "Mexico's clean energy sector", en: http://www.mexicotradeandinvestment.com/pdf/Factsheet\%20 Clean\%20Energy\%20jan10.pdf (recuperado en octubre de 2010). 
las primeras tres compañías está prácticamente orientada a la exportación al mercado estadounidense, con lo que continúan el patrón de "producir en México para vender en Estados Unidos". ${ }^{22}$

Entonces, en resumen $i C u a ́$ les han sido los logros obtenidos en materia ambiental a cinco años de la firma del Acuerdo para el Fortalecimiento de la Asociación Económica entre México y Japón? Lamentablemente éstos no han ido más allá de reuniones de representantes de ambos gobiernos. El primer encuentro entre ambas partes se dio con la visita de los senadores de la Comisión Mexicana de Energía a Japón, en 2005, con el fin de conocer algunas acciones y proyectos privados y públicos en Japón vinculados con el desarrollo de las energías renovables. ${ }^{23}$ En reuniones posteriores del mismo nivel se mantuvo el discurso de la necesidad del consumo eficiente de la energía y la necesidad de la reducción del impacto sobre el medio ambiente. ${ }^{24}$ Sin embargo, estas afirmaciones iban acompañadas de declaraciones en el sentido de que no se debe acceder a compromisos que pongan en riesgo el crecimiento económico. Las energías renovables, entonces, son vistas como un medio de producción más que puede permitirle a las economías mantener su crecimiento sostenido - principal factor que provocó el cambio en el medio ambiente mundial, cuyos efectos se están combatiendo hoy día.

\section{c) Pequeñas y medianas empresas}

En el artículo 141 del Acuerdo para el Fortalecimiento de la Asociación Económica entre los Estados Unidos Mexicanos y el Japón se establece la cooperación en materia de pequeñas y medianas empresas (pymes) entre ambas partes con el objeto de mantener el dinamismo de sus respectivas economías

22. Photon (mayo de 2010), "La revolución silenciosa. México no quiere sólo ser fábrica de la industria solar internacional y anhela un mercado local”, Photon. La revista de fotovoltaica, núm. 5, pp. 92-93, en: http://www.solartec.mx/Photon_Solartec.pdf (recuperado en octubre de 2010). Véase también: Royce, Karl (2010), "TPI y Mitsubishi comienzan producción de aspas", Business News Americas, en: http://www.bnamericas.com/news/energiaelectrica/TPI_y_Mitsubishi_comienzan_produccion_de_aspas (recuperado en octubre de 2010).

23. Senado de la República (2010), Informe de Visita de Senadores de la Comisión de Energía a Japón, en: http://www.senado.gob.mx/comisiones//LX/energia/content/informes/Informe_Japon.pdf (recuperado en septiembre de 2010).

24. Coordinación General de Asuntos Internacionales y Relaciones Parlamentarias (9 de febrero de 2010). Cambio climático. Serie Foros Internacionales, núm. 5 b, en: http://www.senado. gob.mx/internacionales/assets/docs/foros_orgint/Cambio_Climatico_Globe.pdf (recuperado en septiembre de 2010). 
y promover un ambiente favorable para el comercio y la inversión bilateral. De acuerdo al artículo citado, esta cooperación podrá incluir: (a) intercambio de información sobre políticas para las pymes para: (i) fortalecer la competitividad de las pymes; (ii) asistir a las pymes para iniciar negocios; $y$ (iii) promover redes empresariales de las pymes; (b) fomento al establecimiento de redes entre entidades apropiadas de ambas partes que proporcionen asistencia a las pymes; $y$ (c) fomento al intercambio de expertos en el desarrollo de las pymes. ${ }^{25}$

¿Por qué la relevancia de las pymes y por qué dedicarles un espacio en el AFAEMJ? Para México, las pequeñas y medianas empresas son el principal generador de empleos, el sostén de un gran número de familias mexicanas y son también un importante eslabón en la cadena productiva puesto que proporcionan los insumos indispensables en el proceso productivo de las grandes corporaciones. En México, la clasificación de estas industrias se hace en función del número de empleados que tienen, de manera que en el Diario Oficial de la Federación del año 2002 se define como micro empresas a aquellas que cuenten con hasta 10 empleados, pequeñas empresas aquellas con 11 a 50 empleados, medianas de 51 a 250 empleados y grandes empresas con 251 o más empleados.

De acuerdo con la información publicada en la página electrónica de la Secretaría de Economía, las micro, pequeñas y medianas empresas (mipymes) generan 52\% del PIB y 72\% de empleos; para el año 2003 existían alrededor de 3 millones de empresas en México, de las cuales más de 99\% se ubicaban en el rubro señalado. ${ }^{26}$ Los datos anteriores hacen evidente la importancia de este sector en el desarrollo mexicano, además de que éste sea considerado en acuerdos como el signado entre nuestro país y Japón.

En este sentido, debemos mencionar que existen programas de cooperación entre México y Japón en materia de pequeñas y medianas industrias desde el año 2001. En ese año se inició un foro de discusión sobre las pymes. Como resultado del acuerdo entre el entonces presidente mexicano Vicente Fox y el primer ministro japonés Junichiro Koizumi, se conjuntaron esfuerzos para fomentar los programas de apoyo a pequeñas y medianas empresas mexicanas. La Embajada de Japón en México y la Secretaría de Economía de México establecieron el Foro de Cooperación para Pymes, incluyendo a los

25. Véase: Acuerdo para el Fortalecimiento de la Asociación Económica entre los Estados Unidos Mexicanos y Japón, en: http://www.economia.gob.mx/swb/work/models/economia/Resource/424/1/images/texto_acuerdo.pdf (recuperado el 10 de septiembre de 2010).

26. Secretaría de Economía. Contacto Pyme de la Secretaría de Economía. Recuperado el 23 de septiembre de 2010 de: http://www.economia.gob.mx/swb/es/economia/p_cpyme_consultoria 
siguientes organismos: JETRO, JICA, Cámara Japonesa de Comercio e Industria de México AC y el Banco Japonés para la Cooperación Internacional como órgano observador.

De este foro se reportan tres reuniones previas a la firma del AFAEMJ: la primera en octubre de 2001, la segunda y la tercera en febrero y septiembre de 2002. El reporte que aparece de los trabajos realizados en el marco del foro es breve e incluye acciones para sectores muy específicos que no dan cuenta de resultados positivos para las pymes mexicanas. ${ }^{27}$ En el marco de los incentivos para las pymes, uno de los sectores que más se ha analizado y del cual podemos encontrar propuestas concretas ha sido el automotriz. El interés japonés de potenciar su producción en México y avanzar en la modernización de redes productivas ha llevado a que sea este sector el que más trabajo reporta en materia de incorporación de pymes a las grandes corporaciones. En 2007, a dos años de la puesta en marcha del acuerdo, durante la Quinta Cumbre de Hombres de Negocios celebrada en Monterrey, Nuevo León, el Embajador de Japón en México, el señor Masaaki Ono, dijo que las empresas japonesas sufrían ante la falta de suministros en México, ya que hacían un esfuerzo por comprar componentes locales, pero a menudo no las encontraban o éstas no eran de la calidad requerida. Afirmó que tanto Nissan como Toyota estaban implementando programas para capacitar al personal con el fin de incentivar el trabajo y la producción de las pymes mexicanas; sin embargo, recalcó que era necesaria la implementación de una técnica manufacturera de alto nivel para desarrollar estas industrias de soporte, lo que a su vez representaría un elemento importante para elevar la competitividad mexicana. ${ }^{28}$

Destaca sin duda el comentario del embajador Ono acerca de lo limitado de la producción de insumos y componentes en México que hagan más eficiente el trabajo de las industrias japonesas; incluso añadió que a pesar de que las corporaciones de su país hacían un esfuerzo por incorporar componentes locales, prevalecía una deficiencia en los incentivos para las industrias soporte que desalentaba a las empresas japonesas para introducir procesos más complejos e importantes en México. Más aún, las corporaciones japonesas deben importar sus insumos lo cual representa un incremento en el déficit de

27. Foro Pymes. Documentos de la Embajada de Japón en México 2001, en: http://www.mx.embjapan.go.jp/sp/mexico-japon/foro-pymes.htm (recuperado el 17 de agosto de 2010).

28. "El país debe salir de su zona de confort", Diario Milenio, en: http://impreso.milenio.com/ node/7139758 (recuperado en septiembre 23 de 2010). 
la balanza comercial con México y hace que el dinamismo de las exportaciones se siga concentrando en aquellas corporaciones con inversión extranjera o con gran trayectoria en el sector exportador, sin ampliar la cartera de empresas exportadoras a partir del establecimiento de cadenas productivas más competitivas que incorporen a las pequeñas y medianas empresas.

En este sentido, Falck afirma:

[...] el modelo mexicano de exportación no se está renovando a sí mismo, por el contrario, ha permanecido atrapado en exportaciones de bajo valor agregado sobre todo del tipo ensamblaje con un uso intensivo de fuerza de trabajo no calificada. Por tanto, la difusión de la subcontratación por las actividades de exportación ha estado limitada en términos de la diseminación de tecnología de punta y la superación del capital humano. ${ }^{29}$

Ya desde el año 2004, el señor Shinji Ogawa responsable de JICA-México, en su visita al centro Pymexporta de la Laguna en Coahuila hacía hincapié en las grandes diferencias entre México y Japón en la rama de las pymes. Mencionó que la forma de trabajar y la manera de percibir la industria por parte de los empresarios mexicanos distaba mucho del modelo japonés. Dijo que después de su visita a diversas pymes reconoció que uno de los principales problemas es la ausencia de profesionistas que las administren, especialistas que trabajen en ellas y falta de integración con las cadenas productivas.

La instalación de empresas japonesas en estas regiones en un inicio demandaba el 15 por ciento de insumos nacionales, porcentaje que ha venido a menos hasta alcanzar actualmente un tres por ciento, gracias a los problemas de calidad de materiales y de entrega a tiempo de los proveedores [...] destacó que uno de los obstáculos para lograr aplicar con éxito el programa no son los empleados, sino los dueños de las empresas. ${ }^{30}$

La incorporación de las pymes a las cadenas productivas incentiva la competitividad del sector productivo, orientado a la exportación y evitando las

29. Falck Reyes, Melba E., "Las relaciones económicas entre México y Japón a 120 años del primer acuerdo", Revista Mexicana de Política Exterior, México, Instituto Matías Romero, SRE, núm. 86, junio 2009, pp. 20- 65, en: http://portal.sre.gob.mx/imr/pdf/8602falck.pdf (recuperado en octubre de 2010).

30. Hernández, Virginia, "Retan a eficientar pymes mediante sistema japonés", El Siglo de Torreón, 2004, en: http://www.elsiglodetorreon.com.mx/noticia/100141.retan-a-eficientarpymes-mediante-sistema-jap.html (recuperado el 12 de octubre de 2010). 
prácticas oligopólicas. Debe darse una incorporación de las pymes superior a $50 \%$ para que el mercado no sea rehén de los grandes monopolios, que dadas sus capacidades tecnológicas controlan las cadenas de valor global mediante transacciones matriz-filial. Es menester que la planta productiva formada por pymes esté desfragmentada y su operación se sustente en redes de innovación, logrando la congruencia mediante modelos de desarrollo regionales cuyas especificaciones serían acordes a cada región.

La experiencia de Japón cuya economía logró el liderazgo mundial a través de los grandes consorcios y ahora ha mutado hacia un modelo donde predominan las pymes. Las pymes japonesas han tratado de depender menos del keiretsu de la empresa "tractora" y han iniciado un proceso de transformación coordinado con las estrategias gubernamentales para desarrollar nuevas empresas pymes o reorientar las ya existentes. ${ }^{31}$

De manera que para Japón las pymes se han convertido en un importante motor del desarrollo y la innovación tecnológica. El gobierno japonés ha incentivado la incorporación de éstas en los procesos productivos a partir de la adecuación y diseño de leyes como la modificación en 1999 a la Ley básica de Pymes y la creación de la Ley de creatividad y la Ley de promoción de nuevos negocios innovadores. Lo anterior debido a que la incorporación de estas industrias requiere de programas y financiamiento para lograr la alta especialización técnica y de mercado que les permita incorporarse competitivamente a la cadena productiva a través de redes empresariales que trabajan bajo el sistema de subcontratación. ${ }^{32}$

Las pymes japonesas son orientadas a satisfacer las necesidades de calidad y especificaciones de producción de la industria que las contrata. En este sentido Japón ha hecho importantes innovaciones; destaca el Modelo Kioto, que es considerado relevante porque los conglomerados en su programa de innovación y competitividad incluyen programas gubernamentales y académicos para el desarrollo tecnológico y especialización de los recursos humanos.

31. Morales, Roberto et al., "Innovación en las pymes: un análisis referencial México-Japón". Ponencia presentada en el Primer Congreso Internacional en México sobre la mipyme: el impacto de la investigación académica en el desarrollo de la mipyme. Pachuca, Hidalgo el 2 de septiembre de 2009 p. 2, en: http://cocyteh.hidalgo.gob.mx/descargables/ponencias/Mesa\%20V/7.pdf (recuperado el 2 de agosto de 2010).

32. Ibidem, p. 8. 
De acuerdo con Kathryn Ibata-Arens, las pymes japonesas han logrado una incorporación exitosa en los procesos productivos debido a la innovación tecnológica que incorporan a su proceso productivo la especialización de los nichos de mercado que atienden y porque tienen una vocación claramente orientada al exterior. Estas estrategias están sustentadas en el apoyo de diferentes sectores, por ejemplo, tienen apoyo financiero accesible tanto desde el punto de vista de los requisitos y trámites hasta el número y monto de los fondos disponibles para este sector, así mismo, el sector educativo ha creado importantes programas de innovación y capacitación para atender las demandas de las Pymes. ${ }^{33}$

En México, las pequeñas y medianas empresas, si bien son las que mantienen a la economía, representan el eslabón más endeble de la cadena de producción, debido a que, como plantean Salgado y Perusquía:

[...] por lo general [estas empresas] carecen de sistemas de planeación, organización, administración y control eficientes, así como de tecnologías propias [...] Entre los problemas más importantes relativos a las pymes destacan la inadecuada articulación de nuestro sistema económico, que favorece casi prioritariamente a las grandes empresas y corporaciones; políticas gubernamentales inadecuadas; corrupción administrativa en el sector público; falta de financiamiento; inapropiada infraestructura técnico-productiva; carencia de recursos tecnológicos; la casi nula aplicación de adecuados sistemas de planificación empresarial; competencia desleal del comercio informal; globalización y prácticas desleales a nivel internacional; y en general, la carencia de una cultura empresarial. ${ }^{34}$

Por lo que respecta al rubro de la innovación tecnológica, en México encontramos que la producción de conocimiento científico está en manos de las universidades y los centros de investigación y ha habido una tendencia a aislar la investigación de la empresa y la producción.

La persistente falta de interacción entre la oferta y demanda de conocimiento y de investigación científica, obedece a la insuficiencia de los mecanismos de vinculación entre los actores del sistema de ciencia y tecnología y las empresas,

33. Ibata-Arens, Kathryn, Innovation and Entrepreneurship in Japan: Politics, Organizations and High Technology firms, Cambridge, Cambridge University Press, 2005.

34. Salgado, Lisette y Perusquía, Juan Manuel, "Pymes mexicanas, su reto frente a la globalización”, Boom Económico, núm. 8, Cetys Universidad, México, 29 de octubre de 2007, en: http:// www.mxl.cetys.mx/ci/vocetysimpreso/imagenes/BE8.pdf (recuperado el 20 de julio de 2010). 
que facilitara y garantizara la transferencia de conocimientos. Esta insuficiencia también se manifiesta en la falta de fluidez del capital humano hacia la empresa para aumentar su capacidad de absorción. ${ }^{35}$

Si bien el gobierno mexicano ha alentado la institucionalización de espacios que impulsen a las Pymes, como la Subsecretaría para la Pymes de la Secretaría de Economía, los programas de emprendedores, de incubadoras y aceleradoras tanto a nivel nacional como en las entidades federativas, no hay un eje articulador que vincule los esfuerzos para apoyar a este sector en el marco de una estrategia planificada e incluyente. De manera que los incentivos son sectoriales, locales y muy limitados.

Lo anterior nos permite ver la diferencia en la incorporación de las Pymes en el sector productivo de México y de Japón. Como dice Diana Serrano, en este caso es conveniente considerar el papel que desempeña el gobierno y sus secretarías en los casos de Japón y de México debido a que en cada país y en cada dependencia el sector empresarial tiene una connotación diferente; por ejemplo, en el caso japonés el gobierno central diseña y coordina los programas para la pequeña y mediana industria y los ejecuta a través de los ministerios, como el de Industria y Comercio Internacional, otorgando un importante presupuesto para que se cumplan los proyectos.

En el caso mexicano, el gobierno federal no ha logrado consolidar una política amplia y de incentivos a las pymes, a pesar de la cantidad de programas que se tienen y que dependen directamente del gobierno federal (alrededor de 150), el impacto real en las pymes no es relevante, ya que como menciona Serrano "por cada peso que se presupuesta para fines de beneficio de las micro, pequeñas y medianas empresas, en el mejor de los casos les llegan 30 centavos, situación que responde a una amplia estructura burocrática, más que a la atención de sus principales objetivos, cuyos resultados se traducen en confusión y desinformación de parte de los empresarios". ${ }^{36}$

35. Morales, Roberto et al., Innovación en las pymes: un análisis referencial México-Japón. Ponencia presentada en el Primer Congreso Internacional en México sobre la mipyme: el impacto de la investigación académica en el desarrollo de la mipyme, Pachuca, Hidalgo México, 2 de septiembre de 2009, en: http://cocyteh.hidalgo.gob.mx/descargables/ponencias/Mesa\%20V/7.pdf (recuperado el 2 de agosto de 2010).

36. Serrano, Diana E., "Análisis comparativo de la legislación de la pequeña y mediana empresa (pymes) en México y Japón”, Revista México y la Cuenca del Pacífico, vol. 8, núm. 25, Universidad de Guadalajara, México, mayo-agosto, 2005, p. 44 
Un punto importante que marca la diferencia entre el diseño de la política japonesa y la mexicana para apoyar a las pymes y para vincularlas con las cadenas productivas de alta tecnología y de vocación exportadora es que la política japonesa está diseñada desde el nivel macro hasta el micro-regional de manera integral, incluyendo todas las deficiencias y necesidades de estas industrias y destinando recursos a aquellas áreas en donde se requiere mayor protección, especialmente el de innovación tecnológica; por otro lado, la política de apoyo a las Pymes en México marca grandes objetivos de apoyo e incentivos, pero carece de especificaciones claras, dejando a las pymes la opción de solicitar los recursos de acuerdo a sus necesidades e intereses propios sin articulación real con el sector nacional productivo y competitivo.

Sin duda el AFAEMJ es innovador en el sentido de dejar abiertas las posibilidades de apoyo en sectores que pudiesen incentivar el desarrollo mexicano. El artículo 141 en materia de cooperación ha fomentado proyectos específicos para las pymes a través de sus órganos descentralizados, tal es el caso del proyecto denominado: "Fortalecimiento del Sistema Nacional de Formación y Certificación de Consultores para las Pymes en los Estados Unidos Mexicanos", implementado por la Agencia Internacional de Cooperación de Japón. En dicho programa se advierte que las pymes, como mencionamos anteriormente, representan 99\% del total de las empresas existentes en México, siendo el sector que mayor número de empleos genera, de manera que requiere personal calificado que realice tareas de asesoría y promueva la creación de un sistema estandarizado de formación y acreditación de consultores para las Pymes. ${ }^{37}$

En el marco de este proyecto, el gobierno mexicano a través de la Secretaría de Economía firmó con JICA el Alcance de Trabajo para realizar un estudio del programa para el desarrollo de recursos humanos para las Pymes en México, de julio de 2008 a diciembre de 2009. El estudio tuvo como fin crear un Sistema Nacional de Acreditación e implementar un Sistema Nacional de Formación de Consultores.

Como resultado del estudio, JICA ha reportado una serie de recomendaciones a la Secretaría de Economía con el fin de establecer el Programa Nacional de Consultores para Pymes en México. El 3 de febrero de 2010, tanto JICA como la Secretaría de Economía, a través de la Subsecretaría para la Pequeña y

37. JICA, Proyecto "Fortalecimiento del Sistema Nacional de Formación y Certificación de Consultores para las Pymes en los Estados Unidos Mexicanos", 2009, en: http://www.jica.go.jp/ mexico/espanol/activities/pdf/proyecto11.pdf (recuperado el 4 de agosto de 2010). 
Mediana Industria, firmaron el acuerdo para poner en marcha el Proyecto de Cooperación Técnica para el Fortalecimiento del Sistema Nacional de Formación y Certificación de Consultores para las Pymes en México. Considerando el periodo de cooperación, del $1^{\circ}$ de abril de 2010 al 31 de marzo de 2011, este proyecto tiene como meta formar consultores habilitados para asesorar y fortalecer la competitividad de las Pymes mexicanas. ${ }^{38}$

$\mathrm{Si}$ bien este proyecto se inscribe en el marco de los compromisos del acuerdo, no responde a las necesidades declaradas tanto de la empresa japonesa ubicada en México como de la realidad de las pymes mexicanas. Si las declaraciones del embajador Ono se orientan a la falta de pequeñas y medianas empresas que respondan a las necesidades de la inversión productiva de las grandes corporaciones japonesas y, en el caso mexicano, la evidente desarticulación de las iniciativas políticas y la realidad industrial, la formación de consultores no da respuesta a estas necesidades. Pareciese que la organización de foros sólo tuviera como meta cumplir con el objetivo del artículo 141, pero en realidad ni hay una necesidad japonesa —dado que es más rentable para ellos complementar sus procesos productivos con insumos japoneses-, ni una estrategia mexicana que logre aprovechar el acuerdo más allá de sus objetivos comerciales.

\section{Consideraciones finales}

La revisión de documentos y trabajos orientados a analizar el acuerdo de Asociación con Japón nos permiten identificar como punto de partida el hecho de que este acuerdo es consecuencia y/o resultado de las buenas relaciones y antecedentes de cooperación entre México y Japón patentes en el Acuerdo de Amistad, Comercio y Navegación firmado en 1888. No obstante, consideramos que los lazos de amistad y la historia que nos unen no son condición sine qua non para hacer eficiente el Acuerdo de Asociación Económica vigente desde 2005.

Asimismo, consideramos que el acuerdo marca muy bien, desde la perspectiva jurídica, la no obligatoriedad en el cumplimiento de los compromisos entre las partes, dejando a cada uno de los socios el trabajo de implementar estrategias orientadas al fortalecimiento económico y a la búsqueda de ca-

38. JICA, Proyecto "Fortalecimiento del Sistema Nacional de Formación y Certificación de Consultores para las Pymes en los Estados Unidos Mexicanos", 2009, en: http://www.jica.go.jp/ mexico/espanol/activities/pdf/proyecto11.pdf (recuperado el 4 de agosto de 2010). 
nales de cooperación. Pero - y es relevante decirlo— no podemos hablar de complementariedad, aunque el discurso oficial así lo afirme: los datos aquí trabajados nos muestran una gran disparidad, ya que ponen en evidencia el gran desarrollo japonés y la débil economía mexicana.

En los sectores abordados en este ensayo no hemos encontrado los elementos suficientes para establecer la susodicha complementariedad. Si bien es cierto que el comercio entre ambos países se ha incrementado, México todavía está lejos de superar el déficit que tiene en su balanza comercial con Japón. Así, el comercio — que es la actividad más atendida dentro del marco del acuerdo - no ha tenido los resultados esperados, mientras que se han dejado de lado áreas de oportunidad de las que México podría beneficiarse, especialmente las enmarcadas en el tema de la cooperación bilateral.

En los pasados dos años México y Japón han organizados algunos foros y seminarios de tipo consultivo en materia de cooperación científico-tecnológica, sin que hasta ahora se haya advertido alguna consecuencia efectiva. Aún así, no podemos pasar por alto los esfuerzos del gobierno mexicano liderado por Felipe Calderón para reforzar la asociación estratégica establecida en 2003 (para trabajar juntos en temas de la agenda internacional como el cambio climático). A pesar de que el liderazgo japonés ya no es detentado por Yukio Hatoyama, sino por Naoto Kan, actual Primer Ministro, el hecho de haber viajado a Japón para acordar el impulso de una asociación estratégica global denota que ambos países siguen con los canales de comunicación abiertos y esto es ya un logro per se.

Ambos países reconocen la importancia de fortalecer la relación bilateral y trabajar de manera coordinada, pero la agenda bilateral sólo cobra sentido cuando los temas de interés compartido tienen impacto a nivel global. En febrero, México y Japón convinieron en imprimirle un mayor alcance a la asociación estratégica y, al mismo tiempo, coincidieron en la necesidad de aprovechar al máximo el Acuerdo para el Fortalecimiento de Asociación Económica México-Japón, para favorecer la recuperación de flujos comerciales y de inversión. También coincidieron en darle la máxima prioridad a la cooperación científica y tecnológica. En este sentido, evaluaron de manera muy positiva el programa conjunto de cooperación, que ha favorecido la instrumentación de proyectos de desarrollo en terceros países, básicamente en América Latina y el Caribe..$^{39}$ Acordaron también intensificar el intercambio cultural, educativo

39. La cooperación triangular México-Japón hacia terceros países se sustenta en la experiencia de México en la Cooperación Técnica para el Desarrollo y de Japón en el campo de la Asistencia Ofi- 
y la colaboración académica entre los dos pueblos. Con todo ello, lo que se busca es establecer un plan de acción para una Asociación Estratégica Global entre México y Japón, con el fin de fortalecer aún más el trabajo conjunto entre las dos naciones.

El plan de acción no se limita a lo económico, sino que permitirá trabajar de manera conjunta y coordinada en temas como el cambio climático, el desarme y la no proliferación de armas nucleares, el compromiso de trabajar a favor de la paz, la seguridad y la verificación del proceso de desnuclearización, el apoyo en respuesta a los daños del terremoto en Haití, los proyectos de integración y desarrollo en Mesoamérica, el apoyo para la Agencia de Cooperación Internacional para el Desarrollo, entre otros. ${ }^{40}$

De lo anterior, podemos destacar que la cooperación científico tecnológica no se circunscribe exclusivamente a los márgenes del AFAEMJ, sino que éste actúa como un gran escenario que ha posibilitado y potenciado convenios específicos que buscan hacer más eficiente lo suscrito en el AFAEMJ. Asimismo, la relevancia que han tenido instancias como JETRO, JICA, Monbusho y Fundación Japón crece en un contexto de múltiples retos para ambos países. No debemos olvidar que en el caso de México estamos atestiguando el fin del modelo maquilador y que los inversionistas, no sólo los japoneses, demandan el cumplimiento de una serie de requisitos para traer sus capitales.

En este trabajo hemos remarcado que la ausencia de compromisos sólidos y obligaciones de las partes para cumplir con las propuestas planteadas han convertido al AFAEMJ en lo que exactamente es - una plataforma cuyo único propósito es la obtención de beneficios económicos-. Las razones de este resultado son muy comprensibles: la diferencia en niveles tecnológicos entre México y "la tierra del sol naciente" son sustanciales, por lo que representa

cial para el Desarrollo y tiene tres modalidades: 1) Envío de expertos mexicanos a terceros países, 2) Envío de misiones conjuntas México-Japón hacia América Latina y el Caribe, 3) Cursos de capacitación en México para terceros países. Los países beneficiados con este Programa de Cooperación Conjunto México-Japón son: El Salvador, Guatemala y Paraguay en proyectos que van desde la obtención de proteínas unicelulares hasta el fortalecimiento de capacidades para la gestión integral de residuos sólidos. Véase: Unidad de Relaciones Económicas y Cooperación Internacional, Dirección General de Cooperación Técnica y Científica, SRE, Programa Conjunto de Cooperación México-Japón (PCCMJ), en: http://dgctc.sre.gob.mx/html/coop_int_mex/pdf/ Tarjeta_de_apoyo_Mex_Jap.pdf (recuperado el 29 de agosto de 2010).

40. Véase: Secretaría de Relaciones Exteriores (SRE). Comunicado conjunto México-Japón para la Asociación Estratégica Global y el Crecimiento Económico en el siglo xxI, en: http://portal. sre.gob.mx/japon/pdf/comcon.pdf (recuperado el 29 de agosto de 2010). 
todo un rompecabezas el diseño de una estrategia viable con el fin de igualar los beneficios obtenidos por ambos países en el marco de su acuerdo comercial.

Hasta el momento, México sigue siendo básicamente un proveedor de materias primas para Japón, con muy pocos productos de alto valor agregado. Por su parte, la tan anhelada transferencia de tecnología que debiéramos obtener como uno de los beneficios del acuerdo todavía sigue en lista de espera. Esto es probable que se deba en parte al hecho incontrovertible de que el mayor volumen de los conocimientos tecnológicos pertenecen a empresas privadas, que no fueron las que signaron el acuerdo y que por lo tanto no están interesadas en "poner al descubierto" sus know-how y, por otra parte - aunque duela admitirlo—, por falta de infraestructura adecuada en nuestro país para poder asimilar tales tecnologías.

Es evidente el peso y la importancia que las Pymes tienen en el desarrollo de la economía mexicana, sin duda el acuerdo con Japón abre una opción para favorecer a un sector que no se identifica por su eficiencia y dinamismo. La cadena productiva en México, a diferencia de la japonesa, está desarticulada; mientras en Japón se reportan alrededor de 600 mil Pymes articuladas a los procesos productivos de las grandes corporaciones, en México más de un millón de Pymes que aportan más de 50\% del PIB trabajan de forma aislada, con trabas burocráticas y administrativas y bajos niveles de competitividad.

Consideramos que las acciones logradas en el marco del acuerdo en materia de pymes no responden a las necesidades de este sector en México. La creación de foros y la capacitación de asesores no harán a las Pymes mexicanas -necesitadas de personal técnico especializado, de financiamiento, de una estructura burocrática más flexible y de un sistema tributario que les permita sobrevivir- más eficientes ni mejor articuladas en la cadena productiva. Si la cooperación pudiera darse a través de la vinculación del sector público, el empresarial y el académico, posiblemente el modelo Kioto para las Pymes japonesas, uno de los más reconocidos en el mundo, pudiera instrumentarse en México para abrir mejores oportunidades a las Pymes mexicanas.

Por último, debemos cuestionarnos si la implementación del Acuerdo para el Fortalecimiento de la Asociación Económica México-Japón, está pensada para apoyar el desarrollo mexicano, o bien, para responder a las presiones e intereses de un determinado sector, que poco tiene que ver con el beneficio mutuo y la complementariedad. mi 


\section{Fuentes consultadas}

Acuerdo para el Fortalecimiento de la Asociación Económica entre México y Japón, en: http://www.sice.oas.org/TPD/MEX_JPN/Studies/puntos_s.pdf (recuperado el 2 de septiembre de 2010).

Acuerdo para el Fortalecimiento de la Asociación Económica entre los Estados Unidos Mexicanos y Japón, en: http://www.economia.gob.mx/swb/work/ models/economia/Resource/424/1/images/textoacuerdo.pdf (recuperado el 10 de septiembre de 2010).

Agencia Estadounidense para el Desarrollo Internacional (USAID) (2005), "Advancing Clean Energy Use in Mexico”, en: http://pdf.usaid.gov/pdf_docs/ PDACG052.pdf (recuperado en octubre de 2010).

Altbach, Eric (1998), “Japan pledges new aid for Africa”, Japan Economic Institute Bulletin, núm. 41, octubre 30, en: www.jei.org/Archive/JEIR98/9841w4. html (recuperado el 5 de julio de 2003).

Arase, David (1995), Buying Power. The political economy of Japan's foreign aid, Londres, Lynne Rienner Publishers.

Comisión Federal de Electricidad (CFE), Licitación para el primer campo solar (Agua Prieta), en: http://www.cfe.gob.mx/proveedores/licitaciones/ Paginas/Licitaciondelprimercamposolar.aspx (recuperado en octubre de 2010).

Convención Marco sobre Cambio Climático de las Naciones Unidas (CMNUCC), en: http://cdm.unfccc.int/Projects/projsearch.html (recuperado en octubre de 2010).

Coordinación General de Asuntos Internacionales y Relaciones Parlamentarias (9 de febrero de 2010). Cambio climático. Serie Foros Internacionales, núm. 5 b, en: http://www.senado.gob.mx/internacionales/assets/docs/ foros_orgint/Cambio_Climatico_Globe.pdf (recuperado en septiembre de 2010).

De Miguel, Carlos J. (junio 1-2, 2010), "Experience with ex-ante impact assessments and lessons learned", OECD Workshop on "Regional trade agreements and the environment: monitoringimplementation and assessing impacts", París, Francia, en: http://www.oecd.org/dataoecd/18/33/45548090.pdf (recuperado el 21 de octubre).

Donovan, Michael G. y Kwan S. Kim (2002), "Fujimori’s Financiers: How Japan Became the Largest Aid donor in Latin America and Its Implications for 
Future Economic Development", Working Paper 291, enero, en: http:// www.nd.edu/ kellogg/WPS/291.pdf (recuperado el 28 de agosto de 2003). Drucker Colín, René (18 de enero de 2007), "La ciencia no tiene quien la defienda", La Jornada, en: http://www.jornada.unam.mx/2007/01/18/ index.php?section=opinion\&article=022a2pol (recuperado el 16 de octubre de 2010).

EFE ( $1^{\circ}$ de febrero de 2010), "México y Japón firman acuerdo de cooperación tecnológica.", El Universal, en: http://www.eluniversal.com.mx/notas/ vi_655579.html (recuperado el 2 de septiembre de 2010).

Embajada del Japón en México (mayo de 2008). Discurso del embajador Ono en la Cámara de Senadores. Mensaje del Embajador Masaaki Ono en el Foro-Taller sobre el Acuerdo de Asociación Económica entre Japón-México, en: http://www.mx.emb-japan.go.jp/sp/mensaje.html (recuperado el 18 de octubre de 2010).

Falck, Reyes Melba E. (junio, 2009), "Las relaciones económicas entre México y Japón a 120 años del primer acuerdo", Revista Mexicana de Política Exterior, Instituto Matías Romero, SRE, núm. 86, pp. 20-65, en: http://portal.sre. gob.mx/imr/pdf/8602falck.pdf (recuperado en octubre de 2010).

Foro Pymes (2001), Documentos de la Embajada de Japón en México, en: http://www.mx.emb-japan.go.jp/sp/mexico-japon/foro-pymes.htm (recuperado el 17 de agosto de 2010).

Hernández, Virginia (22 de julio de 2004), "Retan a eficientar pymes mediante sistema japonés”, El Siglo de Torreón, en: http://www.elsiglodetorreon. com.mx/noticia/100141.retan-a-eficientar-pymes-mediante-sistema-jap. html (recuperado el 12 de octubre de 2010).

Ibata-Arens, Kathryn (2005), Innovation and Entrepreneurship in Japan: Politics, Organizations and High Technology firms, Cambridge, Cambridge University Press.

JICA (2009), Proyecto "Fortalecimiento del Sistema Nacional de Formación y Certificación de Consultores para las Pymes en los Estados Unidos Mexicanos", en: http://www.jica.go.jp/mexico/espanol/activities/pdf/ proyecto11.pdf (recuperado el 4 de agosto de 2010).

Ministerio de Asuntos Exteriores (28 de enero, 2009), Orientación básica de la política exterior de Japón. Discurso del Ministro de Relaciones Exteriores Hirofumi Nakasone sobre la Política General ante la 171 sesión de la Dieta, en: http://www.mx.emb-japan.go.jp/sp/discurso2.html (recuperado el 29 de octubre 2010). 
Morales, Roberto et al. (2 de septiembre de 2009), "Innovación en las pymes: un análisis referencial México-Japón”. Ponencia presentada en el Primer Congreso Internacional en México sobre la mipyme: El impacto de la investigación académica en el desarrollo de la mipyme. Pachuca, Hidalgo, en: http://cocyteh.hidalgo.gob.mx/descargables/ponencias/Mesa\%20V/7. pdf (recuperado el 2 de agosto de 2010).

OECD (2010), "Education: Governments should expand tertiary studies to boost jobs and tax revenues", en: http://www.oecd.org/document/52/0 ,3343,en_2649_37455_45925620_1_1_1_1,00.html (recuperado el 19 de octubre de 2010).

OECD (2010), "Gross domestic expenditure on R\&D. As a percentage of GDP. Science and Technology: Key tables from OECD”, en: http://www.oecdilibrary.org/docserver/download/fulltext/191000011e1t002.pdf?expire $s=1287384401 \& i d=0000 \&$ accname $=$ guest $\&$ checksum $=52 \mathrm{FA} 62 \mathrm{BC} 628 \mathrm{C} 0$ C0CF97CB2A091B5AE29 (recuperado el 17 de octubre de 2010).

Pemex (2009), "Reservas de hidrocarburos al 1 de enero de 2010", Memoria de Labores 2009, pp. 77-86, en: http://www.pemex.com/files/content/4_ MLab_2009.pdf (recuperado en octubre de 2010).

Photon (mayo de 2010), "La revolución silenciosa. México no quiere sólo ser fábrica de la industria solar internacional y anhela un mercado local", Photon. La revista de fotovoltaica, 5, pp. 92-93, en: http://www.solartec. mx/Photon_Solartec.pdf (recuperado en octubre de 2010).

Presidencia de la República (2007), Plan Nacional de Desarrollo, en: http://pnd. presidencia.gob.mx/ (recuperado en septiembre de 2010).

Programa Conjunto de Cooperación México-Japón (PCCMJ), en: http://dgctc. sre.gob.mx/html/coop_int_mex/pdf/Tarjeta_de_apoyo_Mex_Jap.pdf (recuperado el 2 de septiembre de 2010).

Ramos, Jorge (31 de enero de 2010), “Calderón llega a Japón a visita oficial”, El Universal, en: http://www.eluniversal.com.mx/notas/vi_655353.html (recuperado el 29 de agosto de 2010).

Ramos, Jorge (31 de enero de 2010), "Cambios legales dan certidumbre: Ruiz”, El Universal, en: http://www.eluniversal.com.mx/primera/vi_34362. html (recuperado el 29 de agosto de 2010).

Ramos, Jorge (1 de febrero de 2010), "Calderón pacta con Japón atender problemas globales”, El Universal, en: http://www.eluniversal.com.mx/ notas/vi_655531.html (recuperado el 29 de agosto de 2010). 
Ramos, Jorge (1 de febrero de 2010). "FCH se reunió con legisladores de Japón”, El Universal, en: http://www.eluniversal.com.mx/notas/vi_655523. html (recuperado el 29 de agosto de 2010).

Ramos, Jorge (1 de febrero de 2010), "FCH ofrece a japoneses oportunidades en el sector energético", El Universal, en: http://www.eluniversal.com.mx/ notas/vi_655510.html (recuperado el 29 de agosto de 2010).

Ramos, Jorge (1 de febrero de 2010), "FCH presume en Japón 'narco lucha' y economía”, El Universal, en: http://www.eluniversal.com.mx/nacion/ vi_175344.html (recuperado el 29 de agosto de 2010).

Ramos, Jorge (1 de febrero de 2010), "Japón ofrece capacitación en seguridad”, El Universal, en: http://www.eluniversal.com.mx/notas/vi_655525.html (recuperado el 29 de agosto de 2010).

Rix, Alan (1980), Japan's Economic Aid, Nueva York, St. Martin's.

Rosenstein-Rodan, P.N. (1970), "International Aid for underdeveloped countries”, en J. Bhagwati y R. S. Eckhaus (eds.), Foreign Aid, Londres, Penguin. Royce, Karl (2010), “TPI y Mitsubishi comienzan producción de aspas”, Business News Americas, en: http://www.bnamericas.com/news/energiaelectrica/TPI_y_Mitsubishi_comienzan_produccion_de_aspas (recuperado en octubre de 2010).

Salgado, Lisette y Perusquia, Juan Manuel (29 de octubre de 2007). "Pymes mexicanas, su reto frente a la globalización”, Boom Económico, núm. 8, cETYs Universidad, en: http://www.mxl.cetys.mx/ci/vocetysimpreso/imagenes/BE8.pdf (recuperado el 20 de julio de 2010).

Secretaría de Economía, oficina de representación en Japón (enero de 2010), Mexico's clean energy sector, en: http://www.mexicotradeandinvestment. com/pdf/Factsheet\%20Clean\%20Energy\%20jan10.pdf (recuperado en octubre de 2010).

Secretaría de Economía (2010), Contacto Pyme de la Secretaría de Economía, en: http://www.economia.gob.mx/swb/es/economia/p_cpyme_consultoria (recuperado el 23 de septiembre de 2010).

Secretaría de Relaciones Exteriores (SRE), Comunicado conjunto MéxicoJapón para la Asociación Estratégica Global y el Crecimiento Económico en el siglo XXI, en: http://portal.sre.gob.mx/japon/pdf/comcon.pdf (recuperado el 29 de agosto de 2010).

Senado de la República (2010), Informe de Visita de Senadores de la Comisión de Energía a Japón, en: http://www.senado.gob.mx/comisiones//LX/ 
energia/content/informes/Informe_Japon.pdf (recuperado en septiembre de 2010).

Sistema de Información sobre Comercio Exterior (SICE) de la Organización de los Estados Americanos. Acuerdo de Asociación Económica MéxicoJapón, en: http://www.sice.oas.org/Trade/MEX_JPN_s/JPN_MEXind_s. asp (recuperado en octubre de 2010).

Serrano, Diana E. (mayo-agosto, 2005), "Análisis comparativo de la legislación de la pequeña y mediana empresa (pymes) en México y Japón”, México y la Cuenca del Pacífico, vol. 8, núm. 25, Universidad de Guadalajara.

Solís, M. y Katada, S. N. (2007), "The Japan-Mexico FTA: A Cross-Regional Step in Japan's New Trade Regionalism”, Pacific Affairs, vol. 80, núm. 2, pp. 279-300.

The World Economic Forum (2010), The global competitiveness report 20102011, en: http://www3.weforum.org/docs/WEF_GlobalCompetitivenessReport_2010-11.pdf (recuperado el 9 de septiembre de 2010).

Tokoro, Yasuhiro (enero, 2006), “México y Japón: una perspectiva del Acuerdo de Asociación Económica”, Economía UNAM, vol. 3, núm. 7, pp. 47-68, en: http://www.ejournal.unam.mx/ecu/ecunam7/ecunam0703.pdf (recuperado el 2 de septiembre de 2010).

Tormo y Asociados (2007), Japón y México apoyarán a pymes automotrices. [Quinta Edición del Foro "México Cumbre de Negocios. Creando la fórmula para México: Crecimiento acelerado, democracia plena, 28-30 octubre, 2007, Monterrey, Nuevo León"], en: www.tormo.com.mx/actualidad/ noticias/noticia.asp?id=160 (recuperado el 13 de agosto de 2010).

Unidad de Relaciones Económicas y Cooperación Internacional, Dirección General de Cooperación Técnica y Científica, SER (junio de 2010). Programa Conjunto de Cooperación México-Japón (PCCMJ), en: http://dgctc. sre.gob.mx/html/coop_int_mex/pdf/Tarjeta_de_apoyo_Mex_Jap.pdf (recuperado el 29 de agosto de 2010).

Vélez, Guadalupe (29 de octubre de 2007), "Alianza estratégica México-Japón", Boom Económico, núm. 8, CETYs Universidad, en: http://www.mxl.cetys.mx/ ci/vocetysimpreso/imagenes/BE8.pdf (recuperado el 20 de julio de 2010). Yamamoto, Tadashi (1978), Philanthropy in Japan. Japan Center for International Exchange, Japón. 